JACOB, F. \& Fuerst, C. R. (1958). J. gen. Microbiol. 18, 518-526

\title{
The Mechanism of Lysis by Phage Studied with Defective Lysogenic Bacteria
}

\author{
By F. JACOB AND C. R. FUERST* \\ Service de Physiologie microbienne, Institut Pasteur, Paris
}

\section{Introduction}

\begin{abstract}
Almost since the discovery of bacteriophage, attempts have been made to analyse the lytic process which allows the infected cell to release the new crop of phage particles. One has thus looked in phage lysates for a substance able to initiate lysis of non-infected cells of the same species. With bacteriophages acting on Gram-positive bacteria, such attempts have frequently been successful (Gratia \& Rhodes, 1923; Wollman \& Wollman, 1932; Gratia, 1937; Evans, 1934 ; Wahl \& Josse Groichot, 1950 ; Maxted, 1957). With phages acting on Gramnegative bacteria, the situation appears to be rather complex. Certain strains of phages form, with certain strains of bacteria, plaques which are surrounded by a halo due to the presence of a lysin, a non-diffusible substance produced during phage multiplication (Sertic, 1929 $a, b$; Sertic \& Boulgakov, 1937). Such substances have now been observed in lysates formed by various phage strains (Anderson, 1945; Panijel \& Huppert, 1956; Huppert \& Panijel, 1956). Their lytic activity can be demonstrated, not on living cells, but on cells first exposed to ultraviolet radiation (Anderson, 1945) or treated with acetone (Panijel \& Huppert, 1956). The mechanism by which such substances initiate bacterial lysis is not clear and their role in the processes of lysis by phage has not yet been established. A new possibility of investigating the process of lysis by phage is offered by the study of lysogenic systems.
\end{abstract}

\section{Defective lysogenic bacteria}

Lysogenic bacteria carry and transmit to their progeny the genetic information which allows them to produce bacteriophage in the absence of infection with extrinsic particles. It can be demonstrated that, in such bacteria, the genetic material of the phage is present in a non-infectious form, the prophage, bound to a specific locus of the host genetic material. During the growth of lysogenic cells, the development of the prophage, which results in the production of infectious particles and lysis of the host, occurs only in a small fraction of the population. In some lysogenic systems, however, phage production and bacterial lysis can be induced in the whole of the population by exposing the cultures to the action of u.v. radiation (induction, see Lwoff, 1953; Jacob, 1954).

From lysogenic bacteria, variants can be obtained in which a mutation of the prophage prevents some process necessary for the formation of infectious

\footnotetext{
* Present address: The Ontario Cancer Institute, Toronto, Canada.
} 
particles. Strains carrying such mutant prophages are called defective lysogenic strains. They can be isolated either after infection of sensitive bacteria with temperate phages (Jacob, 1950; Lwoff \& Siminovitch, 1951; Arber \& Kellenberger, 1958) or among the survivors of normal lysogenic bacteria exposed to heavy doses of u.v. radiation (Lederberg \& Lederberg, 1953; Appleyard, 1954; Jacob \& Wollman, 1956). In cultures of such bacteria no, or very few, phage particles can be detected.

Genetic analysis of some defective strains of u.v.-inducible Escherichia coli K $12(\lambda)$ has shown that the defective character can be ascribed to prophage mutations which interfere with the normal process of phage production (Jacob \& Wollman, 1956). After u.v. induction, prophage development is initiated but the prophage lesion results in an alteration of one of the steps necessary for the completion of infectious particles, such as maturation. The rate at which infectious particles are formed results from the back mutation of the defective prophage gene to the wild-type allele. Defective lysogenic bacteria offer therefore the remarkable situation of a phage genetic material that can be perpetuated only in the prophage state. Defective mutations can occur at different loci in the prophage linkage-group and each of these mutations appears to result in an alteration of a different step of phage synthesis and morphogenesis.

When a variety of defective lysogenic strains of Escherichia coli K $12(\lambda)$ was examined, it was observed that such strains react differently to u.v. irradiation: some lyse and others do not. Such defective systems therefore provide an opportunity of analysing the process of lysis by phage.

\section{The lysis of defective strains}

When exponential cultures of normal lysogenic Escherichia coli $\mathrm{K} 12(\lambda)$ are exposed to suitable doses of u.v. radiation, bacterial growth first proceeds, although at a decreasing rate, during about 70-80 min. (Fig. 1). During this latent period, no infectious particles are released. Lysis then begins and infectious particles are released into the medium. These processes are completed at about 120-150 min.

When defective strains are exposed to the same dose of u.v. radiation and their pattern of lysis examined, three different types of reactions can be observed, depending upon the strain used:

(1) Some of the defective strains behave as normal lysogenic bacteria. After irradiation, residual growth is observed and lysis occurs after a latent period of $80 \mathrm{~min}$. although no infectious particles can be detected in the lysate (Fig. 2, curve 1).

(2) In other strains, residual growth occurs during the latent period, but at 80 min., when growth stops, no lysis occurs and optical density remains constant for several hours (Fig. 2, curve 2).

(3) In a third type of strain, residual growth does not stop at $80 \mathrm{~min}$. but, instead, proceeds for $2-3 \mathrm{hr}$. The variation in optical density progressively decreases and finally stops (Fig. 2, curve 3).

In u.v.-inducible lysogenic systems, the presence of the prophage confers to the host-bacterium an increased sensitivity to u.v. radiation as compared with 


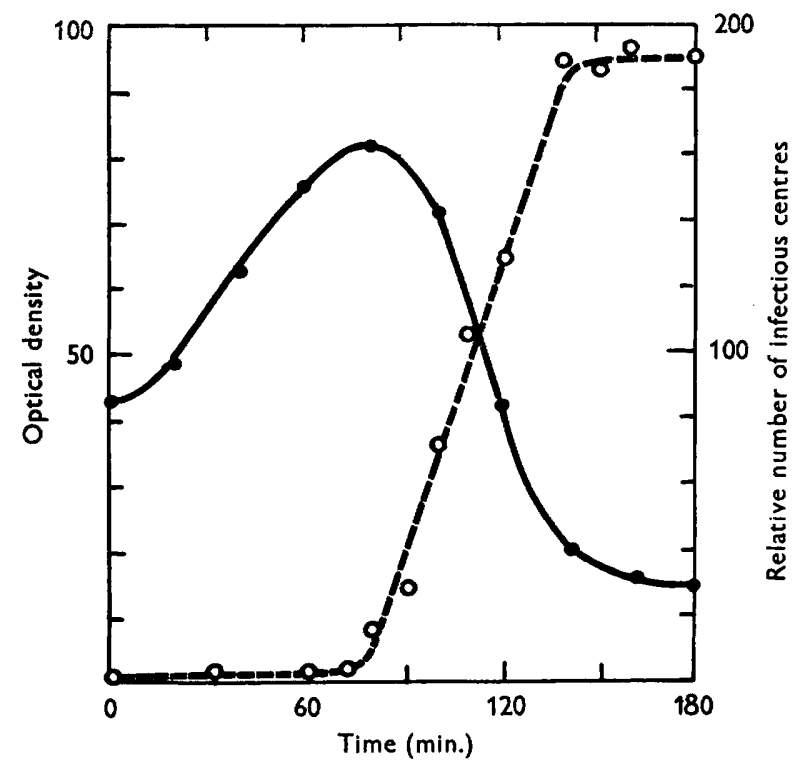

Fig. 1. Ultraviolet-induction of lysogenic Escherichia coli $\mathrm{K} 12(\lambda)$. A culture of exponentially-growing bacteria is exposed to an optimal dose of u.v. radiation (inducing phage production in more than $90 \%$ of the population). The suspension is aerated in broth at $37^{\circ}$. The optical density in arbitrary units and the relative number of infectious centres are plotted against the time of incubation after irradiation.

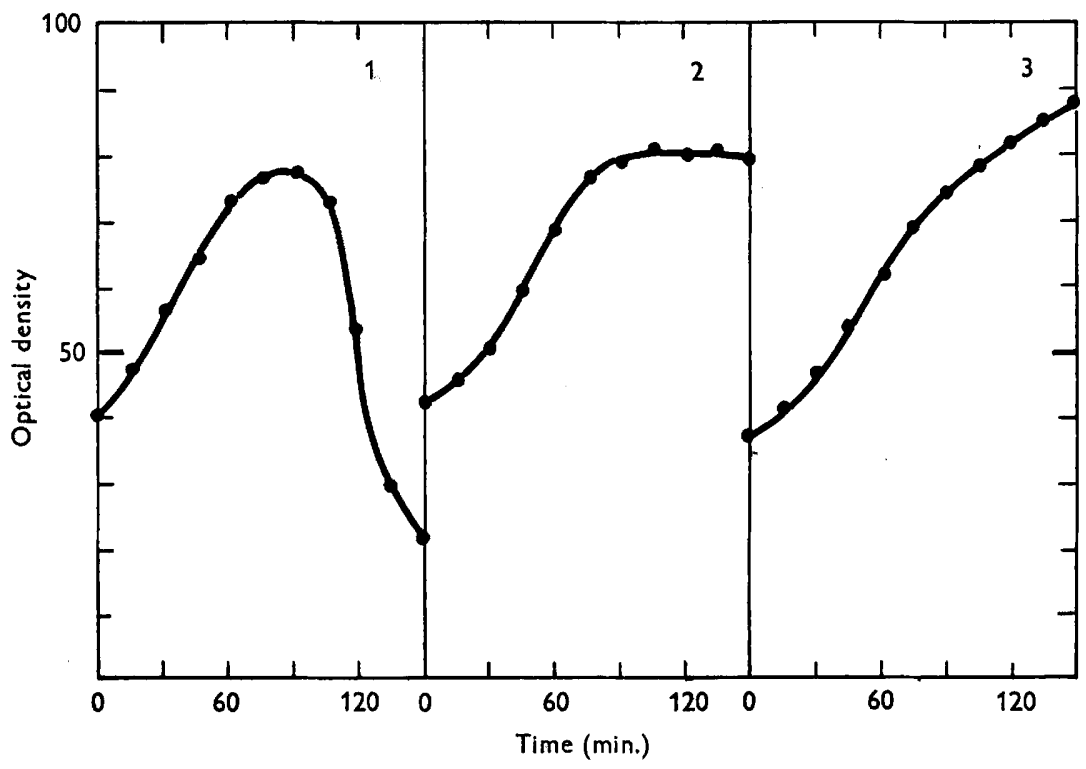

Fig. 2. Different responses of defective lysogenic bacteria to u.v. radiation. Cultures of exponentially-growing bacteria are exposed to an optimal dose of u.v. radiation and aerated in broth at $37^{\circ}$. The optical density is plotted against the time of incubation after irradiation. Curve 1 : strain $\mathbf{P} 32$; curve 2, strain P 30; curve 3, strain P 22. 
homologous non-lysogenic bacteria. When the sensitivity of u.v. radiation of the various defective types is compared with the sensitivity of normal lysogenic and non-lysogenic bacteria, they are found to be as sensitive as normal lysogenic cells. It appears therefore that u.v. radiation initiates, even in the strains which do not lyse, an abortive development of the prophage which results in an increased sensitivity to $u . v$. radiation.

The existence of different possible reactions to u.v. radiation, as far as lysis is concerned, indicates that the processes determining bacterial lysis may or may not be initiated in the course of prophage development, according to the type of lesion controlled by the prophage mutation. Comparison of such defective bacteria therefore allows the possibility of investigating the mechanism of lysis in relation with phage multiplication.

\section{The presence of endolysin in the lysates of induced lysogenic bacteria and its role in the process of lysis by phage}

The mode of action of lysozyme on bacteria has recently been described in detail (Salton, 1952; Tomcsik \& Guex-Holzer, 1952; Weibull, 1953). More especially, it has been found that under defined environmental conditions, lysozyme may also initiate lysis of Gram-negative cells (Repaske, 1956; Zinder \& Arndt, 1956). If bacterial lysis resulting from phage action is really due to the presence of a lytic substance, formed during phage development and acting 'from inside' on infected cells, one may wonder whether such a substance would not require the same conditions as lysozyme in order to act 'from outside' on non-infected cells. Indeed, lysates, obtained either after u.v. induction of lysogenic Escherichia coli $\mathrm{K} 12(\lambda)$ or after infection of sensitive $E$. coli $\mathrm{K} 12$ with $\lambda$ phages, which have been freed from infectious particles by centrifugation, are able to induce lysis of $E$. coli $\mathrm{K12}$, first treated with chloroform or with a salt of ethylene diamine tetra-acetic acid (EDTA) (Fig. 3). If such a lytic activity is really involved in the process of lysis by phage, it must be detected only in the cultures of defective strains which lyse after u.v. irradiation. As a matter of fact, lytic activity can be demonstrated in the lysates of any defective strain which lyses after u.v. irradiation. On the contrary, after ultrasonic disruption of bacteria, a treatment which does not alter the properties of the agent, activity cannot be found, either in growing $E$. coli $\mathrm{K} 12$ strains, or in any induced defective strain which does not exhibit lysis after irradiation (Table 1). However, in the latter case, when bacteria are first u.v.induced and then infected with a normal $\lambda$ phage, lysis occurs and lytic activity is present in normal amount in the lysates.

It therefore seems reasonable to conclude that bacterial lysis, resulting from the development of phage $\lambda$, is correlated with, and probably due to, the presence of a lytic substance which will now be designed as endolysin. Formation of endolysin is not restricted to multiplication of phage $\lambda$, but appears to be a general feature of phage development since the presence of an endolysin has been found in every phage/bacterium system studied so far, i.e. Escherichia coli B-phage T2, E. coli B-phage T5, E. coli K12-phage 21. 


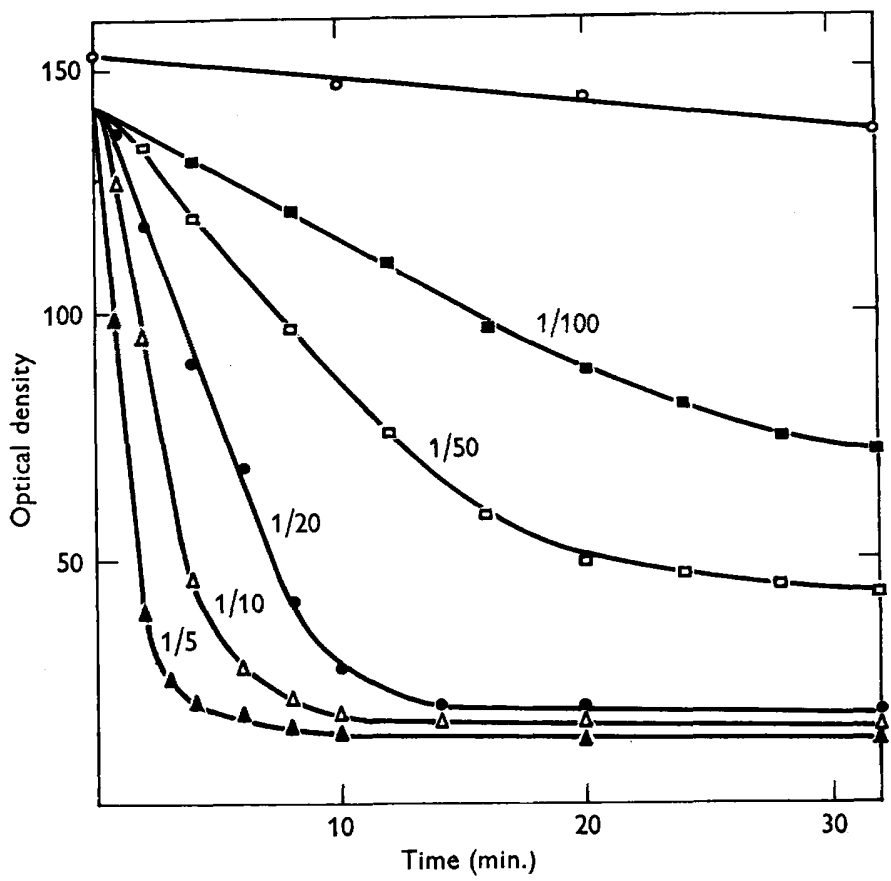

Fig. 3. Action of $\lambda$-endolysin on EDTA preparations of Escherichia coli. A culture of growing $\boldsymbol{E}$. coli $\mathrm{B}$ is centrifuged, washed and the bacteria are suspended in EDTA solution $(0 \cdot 1 \mathrm{M}, \mathrm{pH} 8 \cdot 0) ; 5 \mathrm{~min}$. later the bacteria are centrifuged down, washed and resuspended in distilled water. One ml. of this suspension is added to $1 \mathrm{ml}$. of various dilutions of a lysate obtained after u.v. induction of defective strain $\mathbf{P} 32$. The mixtures are maintained at room temperature. The optical density of the mixtures, in arbitary units, are plotted against time.

\section{Table 1. Detection of endolysin in u.v.-induced cultures of various defective lysogenic Escherichia coli $\mathrm{K} 12$}

Cultures of various defective strains were exposed to an optimal dose of u.v. radiation, and aerated in broth at $37^{\circ}$. The evolution of the optical density was followed as a function of time. Lysates of strains which lyse, or preparations disrupted ultrasonically of strains which do not lyse were assayed for lytic activity against EDTA preparations of $E$. coli B.

$\begin{array}{ccc}\begin{array}{c}\text { Defective } \\ \text { strains }\end{array} & \begin{array}{c}\text { Lysis after } \\ \text { u.v. irradiation }\end{array} & \begin{array}{c}\text { Presence of } \\ \text { endolysin }\end{array} \\ \text { P 14 } & + & + \\ \text { P 15 } & + & + \\ \text { P 16 } & + & + \\ \text { P 17 } & + & + \\ \text { P 18 } & + & + \\ \text { P 19 } & + & + \\ \text { P 21 } & + & + \\ \text { P 32 } & + & + \\ \text { P 34 } & + & + \\ \text { P 22 } & 0 & 0 \\ \text { P 27 } & 0 & 0 \\ \text { P 28 } & 0 & 0 \\ \text { P 29 } & 0 & 0 \\ \text { P 30 } & 0 & 0\end{array}$




\section{Properties of $\lambda$-endolysin}

Very little is known as yet about the properties of endolysin: it is not dialysable; the lytic activity is destroyed by heating at $70^{\circ}$ for $30 \mathrm{~min}$. or after treatment with trypsin. It appears therefore to be a protein or to contain a protein. The lytic activity is not specific since $\lambda$-endolysin is active on EDTA preparations of various strains of Escherichia coli, and in particular on strain B which does not adsorb phage $\lambda$. It acts also on strains of other species, e.g. Haemophilus influenzae. However, this endolysin does not lyse cultures of living Gram-positive bacteria, such as Bacillus megaterium, which are lysed by lysozyme.

Like lysozyme, endolysin appears to act on a component of the bacterial cell wall after EDTA treatment, since in the presence of $2 \mathrm{M}$-sucrose, the cells lose their rod shape and change to small spheres similar to protoplasts. This transformation affects 50-90\% of the population, depending on the preparation. These small spheres are very sensitive to osmotic variations and, like protoplasts, they lyse as soon as they are suspended in distilled water. The chemical nature of the component which behaves as a substrate for endolysin has not yet been analysed.

Endolysin activity may easily be titrated by kinetic measurements of lysis of standard bacterial preparations (Fig. 3). The rate of lysis seems to be roughly proportional to concentration and such a titration appears to be sufficiently accurate for most of the current experiments.

\section{The relationship between endolysin and phage}

In many respects, endolysin appears to be similar to, and perhaps is, the same substance as the 'prolysin' found in u.v.-induced lysates of Escherichia coli $\mathrm{K} 12(\lambda)$ by Huppert \& Panijel (1956). By comparing the action of this substance and of trypsin on acetone-treated bacteria, these authors concluded that the lytic substance acted only indirectly by activating autolytic systems of the bacteria. The known properties of endolysin, and especially the possibility to make protoplast-like spheres in the same conditions as with lysozyme, would suggest that endolysin destroys some cell-wall components which have first to be unmasked by a treatment with chloroform or EDTA. Whether or not the autolytic systems of the bacteria play a role in the lytic process still remains unknown.

The question then arises of whether endolysin is synthesized de novo during phage multiplication, or whether it exists in the cell in an inactive form and is then unmasked during phage development. After u.v. radiation, the lytic activity may be detected at about $35-40 \mathrm{~min}$., i.e. in the middle of the latent period and then it increases until lysis (Fig. 4). When KCN or chloroamphenicol are added at $40 \mathrm{~min}$., no further increase in the lytic activity is observed (Fig. 4). Although not conclusive, this result would suggest that one is dealing here with the de novo synthesis of a protein.

Another point raised by the study of endolysin is the relationship which may exist between the phage produced and endolysin. Is endolysin a phage 
constituent and, if this be the case, is it related with other phage constituents which are known to exert an enzymic activity on components of susceptible cells (Barrington \& Kozloff, 1956; Weidel \& Primosigh, 1958)? Or, on the contrary, does endolysin represent some kind of by-product of phage synthesis?

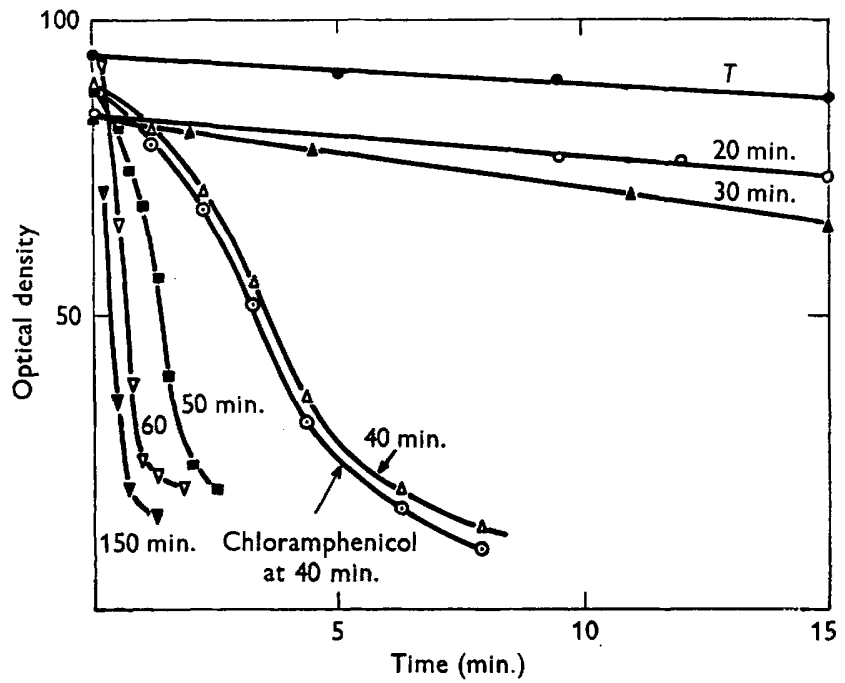

Fig. 4. Variations of lytic activity in u.v.-induced lysogenic cells during the latent period. A culture of defective lysogenic bacteria $P 32$ is induced at time 0 with an optimal dose of $u . v$. radiation and the organisms aerated in broth at $37^{\circ}$. At various times, a sample is cooled and the cells are disrupted ultrasonically with a 'Raytheon'. The extracts are assayed on EDTA preparation of Escherichia coli $\mathbf{B}$ as described in Fig. 3. At 40 min., chloramphenicol $(20 \mu \mathrm{g} . / \mathrm{ml}$.) was added to a sample which was aerated at $37^{\circ}$ during $40 \mathrm{~min}$. Bacteria were then disrupted ultrasonically and the activity assayed. The optical density of the assay mixtures, in arbitrary units, is plotted against time. Figures represent the times at which samples were cooled.

Satisfactory answers to these questions have not yet been obtained. For the time being, one may mention that anti- $\lambda$ serum does not exhibit any activity against endolysin and that purified phage particles do not exhibit measurable lytic activity under the conditions in which endolysin acts. If endolysin is a phage constituent, it must therefore be situated inside the external coat of the particle, and lytic activity might only be recovered from infectious particles which had been disrupted.

\section{Summary and conclusions}

In lysates resulting from the development of phage $\lambda$, a substance, endolysin, may be detected which lyses Gram-negative bacteria in the same conditions as lysozyme does, i.e. after treatment with chloroform or EDTA. Endolysin seems to be a protein. It acts on a component of the bacterial cell wall and, in the presence of $2 \mathrm{M}$-sucrose, transforms the cells into protoplastlike spheres which are very sensitive to osmotic variations. The lytic activity is not specific since endolysin is active on various strains belonging to different 
species. Similar substances have been detected in the lysates resulting from the development of the different phages studied so far.

Evidence that endolysin plays a role in the process of lysis by phage results from a comparative study of defective lysogenic bacteria. Endolysin is found in the lysate of every defective strain which does lyse after u.v. radiation. On the contrary, no endolytic activity has been detected in extracts of any strain which does not lyse after irradiation.

During phage development, endolytic activity appears in the middle of the latent period and increases until lysis. The possible nature of endolysin as well as its relationship with phage constituents are discussed.

One of us (C.R.F.) is the holder of a National Research Council of Canada Post-doctorate Overseas Fellowship.

\section{REFERENCES}

Anderson, T. F. (1945). The role of tryptophan in the adsorption of two bacterial viruses on their host, E. coli. J. cell. comp. Physiol. 25, 17.

APPLEYARD, R. K. (1954). Segregation of new lysogenic types during growth of a doubly lysogenic strain derived from $E$. coli K12. Genetics, 39, 440.

Arber, W. \& Kellenberger, G. (1958). Electron microscopical studies of phage multiplication. IV. Phage related material produced by six defective lysogenic strains derived from $E$. coli $\mathrm{K} 12(\lambda)$. Virology, (in the Press).

Barrington, L. F. \& Kozloff, L. M. (1956). Action of bacteriophage on isolated host cell walls. J. biol. Chem. $223,615$.

Evans, A. C. (1934). Streptococcus bacteriophage: a study of four serological types. U.S. Publ. Hith Rep. 49, 1386.

Gratia, A. (1937). Phénomène du halo: la synergie des bactériophages. C.R. Soc. Biol., Paris, 126, 418.

Gratia, A. \& Rhodes, B. (1923). Action du principe lytique sur les émulsions de staphylocoques vivants et de staphylocoques tués. C.R. Soc. Biol., Paris, 89, 1171.

Huppert, J. \& Panijel, J. (1956). Recherches sur les prolysines. II. Le cas général de la synthèse des prolysines. Ann. Inst. Pasteur, 90, 711.

$\mathrm{J}_{\mathrm{ACOB}}$, F. (1950). Induction de la lyse et de la production de bactériophages chez un Pseudomonas pyocyanea lysogène. C.R. Acad. Sci., Paris, 231, 1585.

$\mathrm{J}_{\mathrm{AcOB}}$, F. (1954). Les bactéries lysogènes et la notion de provirus. Paris: Masson, 176 p. Monographies de l'Institut Pasteur.

J $_{\text {ACOB, }}$ F. \& Wollman, E. L. (1956). Sur les processes de conjugaison et de recombinaison chez Escherichia coli. I. L'induction par conjugaison ou induction zygotique. Ann. Inst. Pasteur, 91, 486.

Lederberg, E. M. \& Lederberg, J. (1953). Genetic studies of lysogenicity in Escherichia coli. Genetics, 38, 51.

Lwoff, A. (1953). Lysogeny. Bact. Rev. 17, 269.

Lwoff, A. \& Siminovitch, L. (1951). Induction par des substances réductrices de la production de bactériophages chez une bactérie lysogène. C.R. Acad. Sci., Paris, 232, 1146.

MAXTED, W. R. (1957). The active agent in nascent phage lysis of streptococci. J. gen. Microbiol. 16, 584.

Panijel, J. \& Huppert, J. (1956). Recherches sur les prolysines. I. La prolysine du phage Fez. Ann. Inst. Pasteur, 90, 619.

REPASKe, R. (1956). Lysis of gram-negative bacteria by lysozyme. Biochim. biophys. Acta, 22, 189. 
Salton, M. R. J. (1952). Cell wall of Micrococcus lysodeikticus as the substrate of lysozyme. Nature, Lond. 170, 746.

Sertic, V. $(1929 a)$. Origine de la lysine d'une race du bactériophage. C.R. Soc. Biol., Paris, 100, 477.

Sertic, V. $(1929 b)$. Procédé d'obtention de variantes du phage adaptées à lyser des formes bactériennes secondaires. C.R. Soc. Biol., Paris, 100, 612.

Sertic, V. \& Boulgakov, N. A. (1937). Sur la sensibilité d'une souche d'E. coli au bactériophage, en relation avec les caractères antigéniques. C.R. Soc. Biol., Paris, 126, 734.

Tomcsik, J. \& Guex-Hoizer, S. (1952). Änderung der Struktur der Bakterienzelle im Verlauf der Lysozym-Einwirkung. Schreiz. Z. allg. Path. 15, 517.

WAHL, R. \& Josse Goichot, J. (1950). Le facteur bactériostatique des lysats bactériophagiques. C.R. Acad. Sci., Paris, 230, 1703.

Weibull, C. (1953). The isolation of protoplasts from Bacillus megaterium by controlled treatment with lysozymes. J. Bact. 66, 688 .

Weidex, W. \& Primosigh, J. (1958). Biochemical parallels between lysis by virulent phage and lysis by penicillin. J. gen. Microbiol. 18, 513.

Wollman, E. \& Wollman, E. (1932). Recherches sur le phénomène de Twortd'Hérelle (bactériophagie). Ann. Inst. Pasteur, 49, 41.

Zinder, N. D. \& Arndt, W. F. (1956). Production of protoplasts of E. coli by lysozyme treatment. Proc. nat. Acad. Sci., Wash. 9, 586. 